\title{
Ler Pessoa à luz de Pessoa: uma interpretação das Odes de Álvaro de Campos
}

\author{
Karina Bersan Rocha *
}

\begin{abstract}
Resumo
A imensa obra de Fernando Pessoa converge num ponto: a busca angustiada pelo conhecimento de si, do mundo e de Deus, em um universo em acelerada transformação. Este trabalho propõe analisar os poemas "Ode triunfal" e "Ode marítima", à luz dos textos filosóficos e estéticos de Fernando Pessoa, especialmente os escritos sobre o Sensacionismo e os "Apontamentos para uma estética não-aristotélica", assinados por Álvaro de Campos, além de outros poemas, tanto do Pessoa ortônimo quanto do heterônimo, no objetivo de observar essa busca e verificar como ela é expressa nos textos poéticos selecionados.

Palavras-chave: Fernando Pessoa. Estética. Ode Triunfal. Ode Marítima.
\end{abstract}

O poema mais conhecido de Fernando Pessoa é, provavelmente, "Autopsicografia", com seus versos "O poeta é um fingidor./ Finge tão completamente/ Que chega a fingir que é dor/ A dor que deveras sente." (PESSOA, 1987, p. 98). E o poema seguinte, "Isto", inicia-se com "Dizem que finjo ou minto/ Tudo que escrevo. Não./ Eu simplesmente sinto/ Com a imaginação./ Não uso o coração.” (PESSOA, 1987, p. 99). Os dois poemas oferecem um prisma sob o qual podemos ler toda a imensa e variada obra do poeta, que converge num ponto: a busca angustiada pelo conhecimento de si, do mundo e de Deus, em um universo em acelerada transformação.

Em Pessoa, a inquietação metafísica, a investigação da Verdade, conduz a uma extensa produção sobre filosofia e estética, além da vasta produção poética; pois, mais do que desejar conhecer e apreender os modos de conhecer, Fernando Pessoa busca alcançar a forma mais adequada à expressão desse conhecer. Afinal, declara: "Eu era um poeta impulsionado pela filosofia, não um filósofo dotado de faculdades poéticas. Adorava admirar a beleza das coisas, descortinar no imperceptível, através do que é diminuto, a alma poética do universo." (PESSOA, 1990, p. 36). Ancorado nesse desejo, * Instituto Federal de Educação, Ciência e Tecnologia do Espírito Santo - IFES. 
Pessoa produz sua obra ortônima e cria os heterônimos, dentre esses, Álvaro de Campos, seu "companheiro de psiquismo" (PESSOA, 2011)1, com ideias muito próximas às do ortônimo. Sujeito marcado pelos caracteres da modernidade, fascinado pela civilização industrial e pela técnica, engenheiro de educação inglesa e origem portuguesa, viajante e cosmopolita sempre com a sensação de ser estrangeiro em qualquer parte do mundo, Campos admira a energia e a força e deseja

Sentir tudo ele todas as maneiras.
Sentir tudo excessivamente
Porque todas as coisas são, em verdade excessivas
E toda a realidade é um excesso, uma violência,
Uma alucinação extraordinariamente nítida
Que vivemos todos em comum com a fúria das almas (...)
(PESSOA, 1987, p. 340 ).

Em seu anelo de "sentir tudo de todas as maneiras", o poeta experimenta uma ânsia de expansão e fusão com todos os elementos do universo, marca reiterada em seus poemas. Discípulo do mestre Caeiro criador do Sensacionismo, consciente de que "nada existe, não existe a realidade, mas apenas sensações" (PESSOA, 1990, p. 441), Campos intensifica as sensações até o delírio e o paroxismo, e deseja ser um "cantor lúcido do mundo moderno", usando para isto poemas longos, permeados de uma linguagem eufórica cheia de onomatopéias, interjeições, metáforas arrojadas em versos livres e muitas vezes longos. Ao aprender a lição do mestre Caeiro, cria sua própria vertente: "Para Campos, a sensação é de fato tudo mas não necessariamente a sensação das coisas como são, e sim das coisas como são sentidas" (PESSOA, 1990, p. 130). Relata o heterônimo:

O que o mestre Caeiro me ensinou foi a ter clareza; equilíbrio, organismo no delírio e no desvairamento, e também me ensinou a não procurar ter filosofia nenhuma, mas com alma. (PESSOA, 1990, p. 153).

Ávido de tudo e passional, deseja todas as sensações no próprio corpo e, segundo Pessoa, "não tem sombra de ética; é amoral, se não positivamente imoral (...). A idéia da perda da inocência duma criança de oito anos ("Ode triunfal”) é-lhe positivamente agradável, pois satisfaz duas sensações muito fortes - a crueldade e a luxúria." (PESSOA, 1990, p. 131).

1 Carta de Fernando Pessoa a Fernandes Lopes datada de 26 de abril de 1919. 
Na busca de Álvaro de Campos por uma poesia autêntica, essas ideias se traduzem em duas obras revolucionárias em sua época: a “Ode triunfal”, escrita em Londres, datada de 1914 e publicada no primeiro número da revista Orpheu em 1915; e a "Ode marítima", escrita provavelmente em 1915 e publicada na revista Orpheu no mesmo ano. Os escritos sobre o Sensacionismo, também de Campos, têm data provável de 1916 e os "Apontamentos para uma estética não aristotélica", assinados pelo poeta, têm data provável de 1924, e foram publicados pela primeira vez na revista Athena, ${ }^{\text {os }} 3$ e 4, em dezembro de 1924 e janeiro de 1925. Essas informações sugerem que as duas Odes, escritas com os princípios dos textos teóricos supracitados, são anteriores a eles, e podem ser o germe, em poesia, desses ideais estéticos. Ainda assim, faremos uma breve exposição dos princípios estéticos, para então passarmos à análise das odes.

\section{O sensacionismo}

"O sensacionismo prende-se à atitude enérgica, vibrante, cheia de admiração pela Vida, pela Matéria e pela Força (...)” (PESSOA, 1990, p. 429). O movimento, fundado por Caeiro e sistematizado por Álvaro de Campos, busca a "sensação imediata e vivida" (PESSOA, 1990, p. 424), como, segundo Campos, existia na Antiguidade Clássica, em uma poesia em que "espírito e matéria são interpenetrados e intertranscendidos” (PESSOA, 1990, p. 431). Três são seus princípios essenciais, cujo reflexo pode ser percebido em toda a obra de Pessoa:

1. Todo o objeto é uma sensação nossa.

2. Toda a arte é a conversão duma sensação em objeto.

3. Portanto, toda a arte é a conversão duma sensação numa outra sensação.

(PESSOA, 1990, p. 426)

Partindo desses princípios, Campos tece várias considerações a respeito da expressão das sensações, sendo o assunto da arte a abstração criadora, a abstração dinâmica, e sua finalidade, aumentar a autoconsciência humana, tornando a humanidade mais preparada para compreender seu estar no universo de forma clara e lúcida, já que tudo que existe são as sensações, e a arte do seu tempo, a arte moderna, deve "cultivar serenamente o sentimento decadente", 
advindo da "falência dos ideais passados e mesmo recentes"; ou "vibrar com toda a beleza do contemporâneo, com toda a onda de máquinas, comércio, indústrias (...)" (PESSOA, 1990, p. 438). Não obstante, é preciso que não nos esqueçamos as palavras de Pessoa: "o que em mim sente "stá pensando" (PESSOA, 1987, p. 78). A sensação vibrante é sempre intermediada, tanto em Pessoa ortônimo como em Campos, pelo intelecto.

\section{Os apontamentos para uma estética não aristotélica}

"Os apontamentos para uma estética não-aristotélica", na linha do sensacionismo, propõem uma "estética baseada, não na idéia da beleza, mas na de força" (PESSOA, 1990, p. 240), diferenciando-se da estética aristotélica, que defende que o fim da arte é a beleza, no sentido da contemplação ou sensação das coisas belas. Força, no sentido que propõe Álvaro de Campos, é energia, força vital, intensidade, e engloba tanto os mecanismos de integração quanto os de desintegração.

Considerando assim, Campos afirma que a arte que se baseia na inteligência é geral, é bela e agrada; mas a que se baseia na sensibilidade é particular, tem força e subjuga. Para ele, a beleza não existe como uma noção em si, mas como uma força que capta não só o intelecto, mas todas as formas de percepção (emoção, intuição...). No entanto, a noção de beleza pode ser também uma força, desde que seja uma ideia de sensibilidade, e não uma "idéia intelectual de beleza" (PESSOA, 1990, p. 245).

Essas ideias retomam a noção de potência proposta por Nietzche, em A origem da tragédia (2003, p. 17), que defende que a disposição para tudo aquilo que é "terrível, maligno, enigmático, aniquilador e fatídico no mundo da existência" corresponde a um "anseio do feio", em oposição a um "anseio de beleza", e é um sinal de superabundância e saúde. A "vontade de poder", no entanto, não se resume ao desejo de domínio pelo poder físico e brutal, mas uma vontade de poder de direito, de acesso a valores e verdades ideais, contra todo tipo de moral. Essa é a proposta estética que percebemos nos “Apontamentos...”, em que Campos deixa clara sua opção por uma estética dionisíaca e vitalista, em oposição a uma estética apolínea e intelectualista, como defendeu Aristóteles, pois 
o artista não-aristotélico subordina tudo à sua sensibilidade, converte tudo em substância de sensibilidade, para assim, tornando a sua sensibilidade abstracta como a inteligência (sem deixar de ser sensibilidade), emissora como a vontade (sem que seja por isso vontade), se tornar um foco emissor abstracto sensível que force os outros, queiram eles ou não, a sentir o que ele sentiu (...) (PESSOA, 1990, p. 244 - destaques nossos).

Ao finalizar seu texto, afirma Álvaro de Campos que só houve três verdadeiras manifestações de arte não aristotélica: Os poemas de Walt Whitman, os poemas de Caeiro, e as odes que publicou na revista Orpheu - a Ode triunfal e a Ode marítima. O que aproxima as duas odes é a poesia dissonante, com destaque para uma experiência de reunir escrita, corpo e sensibilidade. De que forma os ideais estéticos não aristotélicos se cumprem nessas odes?

\section{A “Ode triunfal”}

Em carta a Adolfo Casais Monteiro, Fernando Pessoa explica a gênese dos heterônimos e enuncia sobre Álvaro de Campos: "Num jato, e à maquina de escrever, sem interrupção nem emenda, sugiu a Ode triunfal de Álvaro de Campos - a Ode com esse nome e o homem com o nome que tem" (PESSOA, 1990, p. 96). Em trecho anterior da mesma carta, observa que "escrever à máquina é para mim falar", portanto se conclui que a "Ode triunfal" foi escrita como se em linguagem oral², e é a apresentação de Álvaro de Campos.

Essa ode tem 240 versos escritos em versos livres, lançados em voragem, e retrata um Álvaro de Campos arrebatado pelo seu tempo e pela modernidade, com influências do Futurismo de Marinetti, de Walt Whitman e do mestre Caeiro. O poeta anuncia um rompimento com o passado e busca novas sensações e infração a todas as regras: as da vida e as do verso, que se apresenta irregular, nervoso e permeado por interjeições, onomatopeias, expressões exclamativas, vocabulário técnico e desvios sintáticos.

É uma celebração da modernidade, do triunfo da civilização técnica e industrializada, embora pontue também os problemas dessa civilização, que ao

2 Essa conclusão, instigada pelo poeta, leva-nos novamente a questionar a "naturalidade" de Pessoa, em sua poesia altamente intelectualizada. Sendo o poeta "um fingidor", pode-se compreender também a sua prosa como um fingimento no jogo com o leitor. 
mesmo tempo o fascina e o perturba, desequilibrando todo o seu ser. O texto se inicia evocando a iluminação que, embora dolorosa, permite ao poeta escrever "rangendo os dentes, fera para a beleza disto/ Para a beleza disto totalmente desconhecida dos antigos" (PESSOA, 1987, p. 240). Já nesses versos se percebe a proposta da nova estética, que se confirma na segunda estrofe:

Ó rodas, ó engrenagens, r-r-r-r-r-r-r eterno!

Forte espasmo retido dos maquinismos em fúria!

Em fúria fora e dentro de mim,

Por todos os meus nervos dissecados fora,

Por todas as papilas fora de tudo com que eu sinto!

Tenho os lábios secos, ó grandes ruídos modernos,

De vos ouvir demasiadamente de perto,

E arde-me a cabeça de vos querer cantar com um excesso

De expressão de todas as minhas sensações,

Com um excesso contemporâneo de vós, ó máquinas!

(PESSOA, 1987, p. 240).

O fascínio pelas máquinas e o desejo de se e fundir a elas e a seus maquinismos são uma constante ao longo de todo o texto, em uma vertigem de sensações. Em alguns momentos essa tentativa de fusão chega ao extremo, e se percebe o profundo mal-estar gerado pela ruptura entre o ser e o mundo, como em:

\footnotetext{
Ah, poder exprimir-me todo como um motor se exprime!

Ser completo como uma máquina

Promíscua fúria de ser parte-agente

Do rodar férreo e cosmopolita

(PESSOA, 1987, p. 240).
}

O desejo de superar essa cisão, numa espécie de comunhão dionisíaca com a vida, associa também os motores à natureza tropical, e anula as fronteiras entre presente, passado e futuro, além de promover, no poema, a interseção entre os elementos físicos e a alma:

Em febre e olhando os motores como a uma Natureza tropical Grandes trópicos humanos de ferro e fogo e força Canto, e canto o presente, e também o passado e o futuro, Porque o presente é todo o passado e todo o futuro E há Platão e Virgílio dentro das máquinas e das luzes eléctricas (...) 
Átomos que hão-de ir ter febre para o cérebro do Ésquilo do século cem,

Andam por estas correias de transmissão e por estes êmbolos

e por estes

[volantes,

Rugindo, rangendo, ciciando, estrugindo, ferreando,

Fazendo-me um acesso de carícias ao corpo numa só carícia à alma.

(PESSOA, 1987, p. 240).

E esse desejo chega, sem nenhum pudor, a uma atração erótica por vezes mesmo sádica e masoquista, em que máquinas e pessoas fazem parte de uma mesma engrenagem e os "caixeiros-viajantes, cavaleiros-andantes da Indústria" são "prolongamentos humanos das fábricas e dos calmos escritórios!":

Amo-vos carnivoramente

Pervertidamente e enroscando a minha vista

Em vós, ó coisas grandes, banais, úteis, inúteis

Atirem-me para dentro das fornalhas! (...)

Espanquem-me a bordo de navios!

Masoquismo através de maquinismos!

Sadismo de não sei quê moderno e eu e barulho!

(PESSOA, 1987, p. 242).

Essa aspiração, entretanto, dá lugar por vezes a uma reflexão sobre a decadência da sociedade dessa época, prostituída aos valores burgueses e alienada da crise que se alastrava pelo mundo:

Comerciantes; vários; escrocs exageradamente bem-vestidos; Membros evidentes de clubes aristocráticos;

Esquálidas figuras dúbias; chefes de família vagamente felizes E paternais até na corrente de oiro que atravessa o colete De algibeira a algibeira!

Tudo o que passa, tudo o que passa e nunca passa! (...)

E toda a gente simplesmente elegante que passeia e se mostra E afinal tem alma lá dentro!

(Ah, como eu desejaria ser o souteneur disto tudo!)

(PESSOA, 1987, p. 241).

No entanto, ainda que ironize e rechace essa sociedade, também se sente perversamente atraído por ela, como se pode observar no verso parentético 
destacado, e pelo que fecha a estrofe seguinte: "Ah, como todos os meus sentidos têm cio de vós!" (PESSOA, 1987, p. 242).

O desejo febril, no entanto, cede também lugar a uma evocação nostálgica da infância, que promove uma quebra no poema, e a uma reflexão sobre a desimportância de tudo o que não é o Momento (portanto, o que pode ser percebido, e convertido, de imediato, em sensação): "Tudo isso apaga tudo, salvo o Momento" (PESSOA, 1987, p. 244).

Ao final do poema, Campos parece realizar seu intento de se fundir às máquinas e ao universo - "Eu sou o calor mecânico e a eletricidade!" -, mas retoma a consciência de sua individualidade, e da cisão que o separa do mundo, gerando a sensação da falta: "Ah não ser eu toda a gente e toda a parte!” (PESSOA, 1987, p. 245).

\section{A "Ode marítima"}

Em Ode marítima, "uma sinfonia de sensações incompatíveis e análogas" (O. P., p. 259), poema mais extenso de Campos, com 938 versos, o poeta segue uma poesia da violência e do excesso, mas já consciente de que seu desejo de comunhão com o universo não pode se concretizar e "o entusiasmo do primeiro poema é substituído, no segundo, por um tom soturno, quase desesperado, em que fica patente que só o sofrimento e a dor podem representar, senão um rumo, pelo menos uma perspectiva de encontro". (GOULART, 2009, p. 279$80)$.

Nessa ode, Campos, além de se afastar dos preceitos futuristas e de se voltar para seu interior, promove um retorno sobre a própria obra, em questionamento estético que antecipa em muito as idéias expressas nos Apontamentos para uma estética não aristotélica. $\mathrm{O}$ entusiasmo com a civilização industrial, já em declínio no final da "Ode triunfal", aqui é totalmente abandonado e se exacerba o sentimento de não pertencer e de andar sempre em viagem, real e metafórica. É uma ode mais sombria, em que os barulhos, que na primeira ode vêm das máquinas e dos mecanismos modernos, são silenciados e nos deixam ouvir os sons dos mecanismos interiores, por trás da alma, que funcionam sem ser percebidos, e levam à sensação de que uma ameaça está rondando, pois podem parar de funcionar a qualquer momento. Se a Ode triunfal é um poema feito "para fora", pode-se dizer que a Ode marítima é um poema "para dentro", que perscruta os próprios sentimentos do poeta, um homem que chora seus delírios e evoca todo tipo de sofrimentos. 
O poema se inicia com o sujeito poético "sozinho, no cais deserto", a contemplar o cais em uma manhã de verão, e repete a ânsia de se fundir ao universo, neste caso, marítimo:

Todos os mares, todos os estreitos, todas as baías, todos os golfos,

Queria apertá-los ao peito, senti-los bem e morrer!

(PESSOA, 1987, p. 252)

E as coisas navais tornam-se "meus velhos brinquedos de sonho!", que compõem "fora de mim a minha vida interior!" (PESSOA, 1987, p. 252). A viagem para dentro de si mesmo, na contínua busca pela experiência, é metaforizada pelo mar, elemento caro a toda poesia pessoana, fonte do conhecimento estético, como anunciado na própria ode:

Tema de cantos meus, sangue nas veias da minha inteligência, Vosso seja o laço que me une ao exterior pela estética, Fornecei-me metáforas, imagens, literatura, Porque em real verdade, a sério, literalmente Minhas sensações são um barco de quilha pro ar, Minha imaginação uma âncora meio submersa, Minha ânsia um remo partido, E a tessitura dos meus nervos uma rede a secar na praia! (PESSOA, 1987, p. 252)

O mar é a musa a que se evoca e que fornece os recursos para expressar as sensações produzidas pelo desespero de não concretizar o desejo da tentativa de comunhão dionisíaca com a vida, que acentua a impossibilidade de sair de si, mas a inteligência é o elemento a ser alimentado com sangue, que vai alimentar também a percepção e a sensação. As enumerações exageradas, as diversas onomatopéias para expressar o som do mar batendo no casco do barco, as saudações de marinheiros, estrangeirismos em trechos de diálogos e canções de piratas marcam a forma do poema.

O mar de Campos é espaço de mistério e de violência, que se apresenta à vista com o porto e seus paquetes, mas é habitado por piratas, com todo o horror e o fascínio que os acompanha. Aos poucos, como em linguagem cinematográfica que rompe o processo formal da escrita, o poeta é tomado pelo "delírio das coisas marítimas", que o penetram fisicamente (v. 211-3) e o levam a sonhar. É no sonho que a linguagem assume um ritmo alucinado e, mergulhando no universo marítimo, entram em cena os piratas evocados por 
longas onomatopeias, e o poeta torna a buscar a dissolução no universo, com o mesmo erotismo já visto na ode anterior:

Atropelo-me, rujo, precito-me!...

Estoiram em espuma as minhas ânsias

E a minha carne é uma carne é uma onda dando de encontro a rochedos!

(...)

Rompe, por mim, assobiando, silvando, vertiginando,

O cio sombrio e sádico da estrídula vida marítima.

(PESSOA, 1987, p. 255).

Entram em cena e são celebrados os marinheiros e os piratas, as viagens colonizadoras, com todas as conquistas, os saques e escravizações. Também a estes o poeta deseja unir-se e até mesmo ser crucificado, ter suas veias transformadas em enxárcias, ter a pele arrancada, dando vazão ao erotismo com veio masoquista, que se repete ao longo do poema. A selvageria é sempre lembrada, seguem-se gritos e cenas de naufrágios, e é reafirmado o desejo de fundir-se aos piratas, em identificação com a figura feminina:

Misturai-me convosco, piratas!

Vossa fúria, vossa crueldade como falam ao sangue

Dum corpo de mulher que foi meu outrora e cujo cio sobrevive! (PESSOA, 1987, p. 459).

As "orgias de sangues nos mares" trazem "crimes, terror, barcos, gente, mar, céu, nuvens/ brisa, latitude, longitude, vozaria", em que o poeta quer dissolver seu corpo, e sente a canção como "uma linha reta mal traçada dentro de mim..." (PESSOA, 1987, p. 265).

O grito de Jim Barns acirra a violência extrema ligada à sensualidade - "a fúria da pirataria, da chacina, o apetite, quase o paladar, do saque/Da chacina inútil de mulheres e de crianças/ E a sensualidade de escangalhar e partir as coisas mais queridas dos outros" - e irrompe "através de uma imaginação quase literária", mas esse sonho inquieta mesmo o sonhador, que estremece, "lembrando-me dum filho que não tenho e está dormindo tranquilo em casa" (PESSOA, 1987, p. 265).

Essa lembrança dá lugar a uma nova reflexão vinda "de além da aparência das coisas" sobre a "complexidade da vida" e o poeta abre "de repente os olhos, que não tinha fechado", promovendo a alegria "de sair dos sonhos de vez!". O ritmo vai se acalmando e resume a preocupação "apenas com as coisas modernas e úteis", "o novo gênero de vida/ mundana, intelectual, sentimental,/ 
que a era das máquinas veio trazer para as almas". O poeta, depois da "inútil tentativa de fuga da angústia metafísica e da 'vida sentada, estática, regrada e revista" (BERARDINELLI, 2004, p. 72), torna, tranquilamente, a ela.

Cantando o presente, as cidades, as crises e os conflitos modernos, o poeta expressa sua inquietação e seu desejo reiterado de fundir-se a tudo e a todos, e exprime a "íntima identidade que existe entre as sensações e as idéias a que as primeiras estão desde sempre amarradas" (MOISÉS, 1968, p. 294), presentes na duas odes, que é o germe mais intenso dos escritos sobre o Sensacionismo e dos "Apontamentos para uma estética não-aristotélica". A procura do poeta por uma autoidentidade e por um sentido para a existência leva a uma poesia da violência que não responde a estas questões, mas choca, abala e força os leitores, "queiram eles ou não, a sentir o que ele sentiu" (PESSOA, 1990, p.2 44).

Interessante observar que, embora Fernando Pessoa escreva a Armando Côrtes-Rodrigues em janeiro de 1915, dizendo que "Passou de mim a ambição grosseira de brilhar por brilhar, e essoutra, grosseiríssima, e de um plebeísmo artístico insuportável, de querer épater" (PESSOA, 1944, p. 43), característica marcante dessa poesia, que coincide com a introdução das vanguardas modernistas em Portugal e com o lançamento da revista Orpheu, em que as duas odes são publicadas, o que faz parecer que é uma tendência datada; mas tanto os poemas quanto a teorização dessa escrita, que não se resumem a épater, bem entendido, mas que não se furtam a esse gesto, são posteriores, pois os textos teóricos do Sensacionismos datados são de 1916 e os "Apontamentos para uma estética não-aristotélica", publicados em 1924. Se o Pessoa ortônimo não quer épater, delegou essa função ao heterônimo Álvaro de Campos, que se propõe a

Sentir tudo de todas as maneiras

Ter todas as opiniões

Ser sincero contradizendo-se a cada minuto

Desagradar a si próprio pela plena liberalidade de espírito E amar as coisas como Deus.

(PESSOA, 1987, p. 281).

E se revela o heterônimo que mais se aproxima de Pessoa, em seus processos de fingimento: 
Multipliquei-me, para me sentir,

Para me sentir, precisei sentir tudo,

Transbordei, não fiz senão extravasar-me,

Despi-me, entreguei-me, e há em cada canto da minha alma um altar a um

(PESSOA, 1987, p. 279).

[ deus diferente.

Nessa multiplicação, que só é possível na arte, e se frustra sempre com a realidade, Pessoa e Campos concretizam seu desejo de abarcar o universo e nos acordam para a "hora real e nua como um cais já sem navios" (PESSOA, 1987, p. 269).

\begin{abstract}
The immense work of Fernando Pessoa converge on one point: the anguished search for self-knowledge, world and God in a world in constant and accelerated transformation. This work aims to analyze the poems "Ode Triunfal" and "Ode Marítima" in the light of philosophical and aesthetic writings of Fernando Pessoa, especially the writings on "Sensascionismo" (sensationalism) and the "Notes for a non-Aristotelian aesthetics", signed by Alvaro de Campos, and other poems, both Pessoa by himself and his heteronyms, in order to observe this search and the way it is expressed in poetic texts selected.
\end{abstract}

Keywords: Fernando Pessoa. Aesthetics. Ode triunfal. Ode marítima.

Referências

BERARDINELLI, Cleonice. Fernando Pessoa: outra vez te revejo. Rio de Janeiro: Lacerda, 2004.

GOULART, Audemaro Taranto. Ode marítima. In: Asas da palavra: revista de Letras. Belém: Unama, v. 12, n. 25, jun 2009. p. 277-286.

MOISÉS, Massaud. A literatura portuguesa. 6. ed. São Paulo: Cultrix, 1968. NIETZCHE, Friedrich. A origem da tragédia. São Paulo: Companhia das 
Letras. 2003.

PESSOA, Fernando. Obra poética. Rio de Janeiro: Nova Aguilar, 1987.

PESSOA, Fernando. Obras em prosa. Rio de Janeiro: Nova Aguilar, 1990.

PESSOA, Fernando. Carta a Fernandes Lopes datada de 26 de abril de 1919. Disponível em: <http://www.astormentas.com/din/poema. asp?key $=778 \&$ titulo=CARTA\%20II $>$. Acesso em: 26 set. 2011.

PESSOA, Fernando. Cartas de Fernando Pessoa a Armando Côrtes-Rodrigues (Introdução de Joel Serrão). Lisboa: Confluência, 1944, p. 43. Disponível em: $<$ http://arquivopessoa.net/textos/3510>. Acesso em: 26 set. 2011. 
